\title{
Hava Lojistiği: Bibliyometrik Bir Analiz
}

\author{
Ramazan ERTURGUT*, Tahsin ALTINKURT**
}

Öz

Hava lojistiği malların, bilginin, hizmetin; hızlı, dakik, güvenli ve maliyet etkili akışını sağladığı için lojistik faaliyetler içerisinde önemli bir yere sahiptir. Bu çalışmada, hava lojistiği üzerine yazılan makalelerin bibliyometrik analiz yöntemiyle tahlil edilmesi ve araștırmacılara bu yazınla ilgili bilgiler sunulması amaçlanmıştır. Bu bağlamda hava lojistiği üzerine yapılan çalışmalar betimsel olarak tahlil edilmiş ve bibliyometrik analiz yöntemiyle sunulmuştur. Çalışmanın ilerlemesi için araştırmada kullanılan veriler, Web of Science (WOS), Scopus ve EBSCO veri tabanlarından toplanmıștır. Toplanan verilerle elde edilen bilgiler hava lojistiği yazınındaki eksikleri araştırmacılara göstermesi açısından önemlidir. Bibliyometrik analiz çalışmasıyla hem literatür ölçülmüş hem de ortaya çıkan yeni konuların, kavramların yorumlanmasına yer verilmiștir. Elde edilen bulgularda hava lojistiği ile ilgili en az çalışma yapılmış alanlar; hava lojistik kümelenmesi, hava lojistiğinde küresel park, hava lojistiği entegrasyonu, hava kargosu için alternatif meydan seçimi, hava kargosu üzerine elektronik düzenlemeler ve diğerleridir. Bu alanda çalıșma yapacak araştırmacılara yol göstermesi açısından yapılan bu bibliyometrik analiz faydalı olacaktır.

Anahtar Kelimeler: Lojistik, Havacılık, Hava lojistiği, Havacılık lojistiği, Bibliyometrik analiz

\section{Air Logistics: A Bibliometric Analysis}

\section{Abstract}

Air logistics has a significant place in logistic activities as it enables a rapid, punctual, safe and cost effective flow for goods, information and services. This study aims is to analyze papers on air logistics through bibliometrics and provide information about the literature to researchers. In this scope, studies on air logistics are descriptively analyzed and presented with the bibliometric analysis method. Data used in the study is collected through databases such as Web of Science, Scopus and EBSCO to make sure that the study proceeds. Information gathered through data obtained from studies is important because it shows the shortcomings in air logistics literature for researchers. The relevant literature was assessed and new topics and concepts were interpreted by bibliometrics. Findings indicate that the least studied fields in air logistics are; air logistics

\section{Özgün Araştırma Makalesi (Original Research Article) \\ Geliş/Received: 21.03 .2020 \\ Kabul/Accepted: 11.01 .2021 \\ DOI: https://dx.doi.org/10.17336/igusbd.705333}

* Prof. Dr., Akdeniz Üniversitesi, Uygulamalı Bilimler Fakültesi, Uluslararası Ticaret ve Lojistik Bölümü, Antalya, Türkiye, E-posta: rerturgut@akdeniz.edu.tr ORCID https://orcid.org/0000-0002$\underline{0240-5787}$

** Öğr. Gör., Alanya Alaaddin Keykubat Üniversitesi, Gazipaşa Mustafa Rahmi Büyükballı Meslek Yüksekokulu, Ulaştırma Hizmetleri Bölümü, Sivil Hava Ulaştırma İșletmeciliği Programı, Antalya, Türkiye, E-posta: tahsin.altinkurt@alanya.edu.tr ORCID https://orcid.org/0000-0001-8378-4370 
clustering, global parking in air logistics, air logistics integration, alternative area selection for air cargo, electronical arrangement on air cargo, and others. The bibliometric analysis will be beneficial for the researchers considering working in this field in terms of guiding their studies. analysis

Keywords: Logistics, Aviation, Air logistics, Aviation logistics, Bibliometrics

\section{Giriş}

Uluslararası ticarette ve lojistikte, tedarik zincirinin önemli bir parçası olan hava lojistiğinin betimsel bibliyometrik incelemesi yapılmıștır. Bu çalışmada hava lojistiği ile ilgili veriler; WOS, Scopus ve EBSCO üzerinden toplanmıștır. Bu portallarda yayınlanan erişime açık makaleler çalışılan alanlara, anahtar kelimelere, yazarlara, yazarların aldığı atıflara, yazarların makalelerini yazarken atıf yaptıkları diğer çalıșmalara göre incelenmiștir. Çalıșmada kısıt olarak hava lojistiğine ulaşılacak anahtar kelimeler tespit edilmiş olup bu kelimeler veri tabanlarında, İngilizce dilinde başlık esasına göre araştırılmıştır. Yapılan taramalar sonucunda elde edilen kaynaklar bibliyometrik analiz yöntemi ile incelenmiş ve sonuçlar betimsel olarak verilmiștir.

Bibliyometrik çalışmalar; hem literatürün ölçülmesinde hem de ortaya çıkan yeni konuların, kavramların yorumlanmasında kullanılmaktadır. Bununla beraber bilimsel olan yayınların konuların, yayınlandıkları dergilerin, yazarların ve aldıkları atıfların sayısal ve sayısal olmayan verilerini de içermektedir. Buna ilaveten bu veriler, bireysel araştırmacıların, araştırma gruplarının, kurum/kuruluş ve ülkelerin çıktılarını da ölçmek amacındadır. Ayrıca, bu yöntemin bir diğer amacı da, hem ulusal hem de uluslararası ağları belirlemek ve teknolojik gelişmeleri izlemektir (Manual, 2002, s. 203-204). Bibliyometri, belirli bir alanda, bölgede ve dönemde, kişi veya kurumlar tarafindan üretilen yayınlar ile bu yayınlar arasındaki ilişkilerin sayısal analizidir (Ulakbim, 2019). Üzerinde çalışılan her hangi bir konunun literatürünün "ülkelere, yazarlara, yayınlara, yayınların yıllarına, dillere ve konulara" göre dağılımını aktaran yönteme, betimsel bibliyometri denir. Ancak çalıșılan literatürdeki "yazarlar, yayınlar/yazılar, yazıların yayımlandığı ülkeler" arasındaki ilişkilerin atıf yoluyla niceliksel olarak analiz edilmesine ise "değerlendirici" veya "davranışsal bibliyometri" denir (Yılmaz, 2019, s. 44).

Bibliyometrik analiz yöntemiyle bilimsel iletişime ilişkin farklı bulgulara, belgelerin ya da yayınların belirli özelliklerini analiz edilerek ulaşılmaktadır. Bibliyometrik çalışmalar içerisinde yer alan atıf analizi çalışmaları sıklıkla kullanılan kaynakların belirlenmesini sağlamaktadır. (Al ve Coștur, 2007, s. 144). Atıf analizleri birçok yayınla yapılabildiği gibi tek bir dergiyle de değerlendirmelerde kullanılabilmektedir (Garfield, 1972, s. 473). Atıf analizi araştırmaları sonucu ulaşılan bulgular, çalıșma alanına dair bilimsel araștırma faaliyetleri ile kütüphane koleksiyonlarının geliștirilmesinde ve organizasyonunda kullanılabilmektedir (Al ve Coştur, 2007: 144).

Bu çalışmada hava lojistiği kavramı üzerine bilgi verilmiş, hava lojistiği süreçleri üzerine çalışılmış ve hava lojistiğinin betimsel bibliyometrik analizi yapılarak bulgulara ve sonuçlara yer verilmiştir. Hava lojistiği üzerine yapılan kütüphane çalışmaları kapsamında hava lojistiğinde en çok çalışılan konular; hava kargo taşımacılığında ağ tasarım modelleri, hava kargo endüstrisinde sürdürülebilir rekabet, tarife planlama, rezervasyon ve satış stratejileri, fazla satıștır (overbooking). En az çalıșılan konular ise; hava lojistik kümelenmesi, hava lojistiğinde küresel park, hava lojistiği entegrasyonu, hava kargosu için alternatif meydan seçimi, hava kargosu üzerine elektronik düzenlemeler ve diğerleridir. 


\section{Hava/Havacılık Lojistiği}

Hava lojistiği; güvenliği, hızı ve dakikliği vurgulamaktadır (Wang, 2015, s. 202). Modern lojistiğin bileşeni olan hava lojistiği, küçük ve katma değerli malzemenin verimli bir şekilde taşınmasına sunduğu hizmetlerden dolayı uluslararası ticarette önemli rol oynamaktadır. Uluslararası ticaretin gelişmesi, hava lojistiğini geliştirmekte ve bu gelişimle beraber ekonominin geneli ve uluslararası ticaret de gelişmektedir. Ancak hava lojistiğinin gelişmemesi durumunda ekonomik açıdan bazı kısıtlar oluşmaktadır (Zhu ve Yang, 2011, s. 68). Küresel tedarik zincirinin gelişimi ve uluslararası rekabetin artması, hava lojistiğini ekonomik kalkınmada özel bir alanda konumlandırmaktadır. Çünkü ekonomik verimliliği arttırmak, stok maliyetlerini azaltmak, küresel ölçekte hammadde ve emtianın akışını hızlandırmak için küresel tedarik zinciri geliştirilmelidir. Ayrıca hayatın hızlanması, ticaretin ve hizmetlerin daha çabuk karşılanmasına olan talebi de arttırmaktadır. Bu bağlamda hava lojistiği; hızlı, güvenli ve uzun mesafeli malzeme akışı sağlaması gibi karakteristik özellikleriyle modern ekonominin gelişimi açısından önemlidir (Wang ve Liu, 2014, s. 1742).

Hava lojistiği dünyadaki pazarları birbirine bağlamakla birlikte tedarik zincirleri arasındaki eşgüdümü de sağlamaktadır. Çünkü hayat kurtaran ilaçlar, bozulabilir meyve ve sebzeler ve diğer zamana dayalı gönderilerin neredeyse tamamı hava ulaștırma türüyle taşınmaktadır (IATA, 2018, s. 12). Hava lojistiği faaliyetleri, hava taşımacılığından farklı olarak kapıdan kapıya taşımacılığı da kapsayacak şekilde malzemenin başlangıç noktasından alınması, kamyona yüklenmesi, taşınması, varsa ihracat, ithalat ve gümrük prosödürlerinin yapılması, depolanması, elleçlenmesi ve hava taşımacılığı sistemi ile malzemenin varıș meydanına ulaştırılması ve malzemenin nihai varış noktasına akışı ile ilgili bilginin de servis zinciri boyunca paylaşılması süreçlerinden oluşmaktadır. Hava lojistiği, müşteri odaklı faaliyetlerde bulunarak müşterinin maliyetlerini azaltmak için malların taşınmasının yanında tedarik, tasarım, depolama, ihracat, ithalat ve dağıtım gibi ekstra hizmetleri hava kargo operasyonlarından farklı olarak entegre bir șekilde sağlamaktadır (Zhao, 2012, s. 615; Wang, 2015, s. 202). Bu süreçte gerçekleştirilen faaliyetler ve partnerler Şekil'1'de gösterilmiștir.

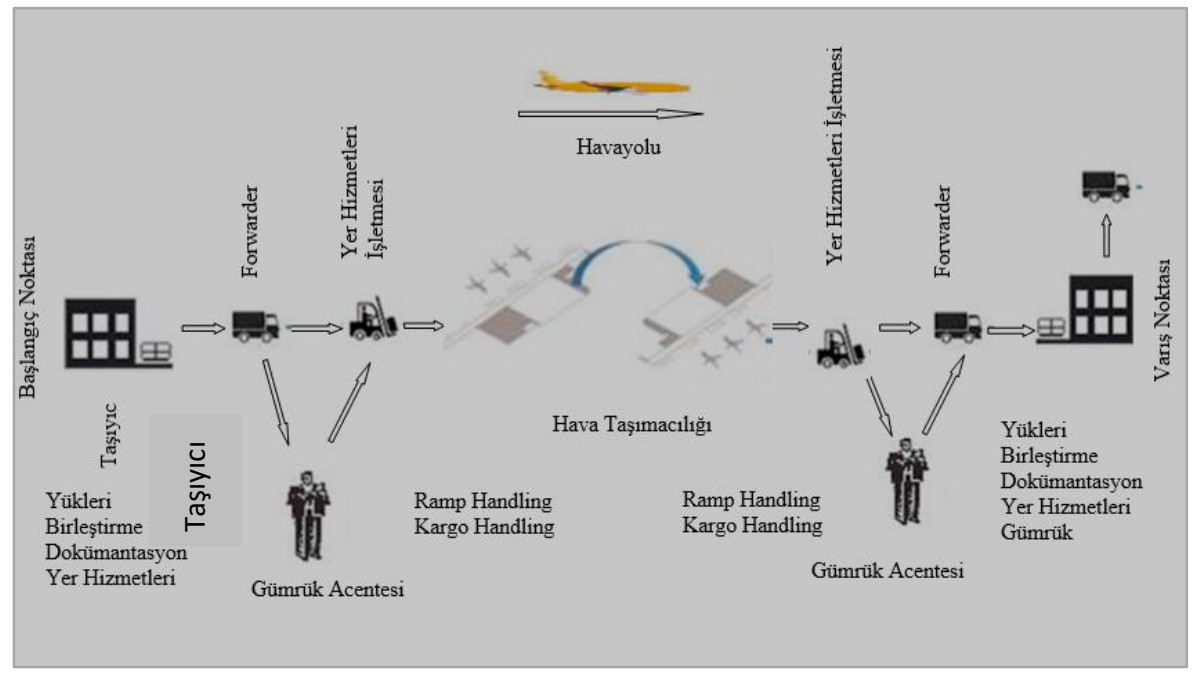

Şekil 1. Hava Lojistiği Tedarik Zinciri Süreci, Hava Lojistiği (Larrodé ve Villagrasa, 2018, s.340; Sales, 2015, s. 62) 
Hava lojistiği, karayolu ile taşınamayan çok büyük gönderileri ve ağır yük parçalarını taşımak için de tercih edilmektedir. Hava lojistiği ile akışı sağlanacak malzemenin güvenliği ve ebatları ile ilgili kısıtlar oluşmakla beraber akışa konu olan malzeme ve emtialara; petrol kuyusu sondaj makinaları, demiryolu lokomotifleri, büyük canlı hayvanlar, yarış arabaları, lokomotifler, moda koleksiyonları, külçe altın, elmaslar, kişisel eşyalar, aşılar ve insan vücudu parçaları örnek verilebilir. Bu operasyonları yük taşıma konusunda alanlarında uzman charter havayolu şirketleri ile charter yük taşıyıcıları gerçekleştirmektedir (Sales, 2016, s. 118-125). Hizmet tedarik zincirinde havayolu şirketleri entegre ekspres taşıyıcılar ve kombine (yolcu ve yükün birlikte taşındığı tür) taşıyıcılar olarak sınıflandırmaktadır (Feng ve Shen, 2015, s. 264). Entegre taşıyıcıların ayırt edici özelliği göndericiden alıcıya kadar tedarik zinciri içerisinde kargo taşımacılığını kendi programlarına göre uygulamalarıdır. Diğer kargo taşıyıcıları ise 3PL hizmeti ve taşımacılık hizmeti sunmaktadır (Lakew, 2014, s. 30). Bu taşıyıcıların sektörde büyümesinin ve navlun miktarının artmasının nedenleri ise aşağıda verilmiştir (aktaran Yuan, Low ve Tang, 2010, s. 215). Bunlar;

$>$ Hafif ancak daha değerli ürünlerin taşınmasına duyulan ihtiyaç,

> Mikro-elektronik ve eczacılık üzerine yeni ürünlerin taşınmasına duyulan ihtiyaç,

$>$ Ürün yaşam döngülerinin kısalması,

$>$ Tam zamanında üretim felsefesinin yaygınlaşması,

$>$ Envanter, depolama ve paketleme maliyetlerine olumlu etkisi,

$>$ Verimlilik artışı ile taşıma maliyetlerindeki düşüşlerdir.

Hava lojistiği, havayolu taşımacılığı sistemi içerisinde lojistik faaliyetler kapsamında ve müșteri beklentileri doğrultusunda malzemenin (hammadde, yarı mamul, bilgi vb.) güvenli, hızlı, dakik ve maliyet-etkili bir şekilde tedarik zinciri boyunca ileri ve geri yönlü akıșını sağlamaktadır. Hava lojistiğinin kavramsal boyutunu içeren anahtar kelimeler; lojistik, lojistik faaliyetler, havacılık güvenliği, havayolu taşımacılı̆̆ı, taşımacılık ve hava taşımacılığı kavramlarından oluşmaktadır.

Lojistik; kelime olarak Yunanca "Logistikos" ve Latince "Logisticus" kelimesinden türemiş olmakla birlikte hesap etmek ve hesaplamak anlamlarına gelmektedir. İkinci Dünya Savaşı sırasında, sınır ötesi gıda, ilaç, asker ve teçhizatın hareketini kapsayan ordu operasyonlarında lojistik önem kazanmıştır. Günümüzde ise lojistik daha geniş bir anlam kazanmış malzemenin tedarikçiden üreticiye ve daha sonra da nihai ürünün işletmeye hareketini ifade eder hale gelmiştir (Kain ve Verma, 2018, s. 3812). Lojistik, malzemenin başlangıç noktası ile varıș noktası arasındaki hareketliliğinin eşgüdümüdür (MÜSİAD, 2015, s.23) İșletmecilik uygulamalarında malzeme yönetme sanatı olarak ifade edilmektedir (Timur, 1998, s. 2).

Lojistik faaliyetler; malzemenin akışı sürecinde gerçekleștirilen; "taşıma, depolama, paketleme ve katma değerli hizmetler, hizmet akışı ile ilgili faaliyetler, gümrükleme, sigorta, muayene, ekspertiz, gözetim, stok yönetimi ve sipariş yönetimi, müşteri hizmetleri" gibi faaliyetlerden oluşmaktadır (MÜSİAD, 2015, s.23).

Havacılık güvenliği; insanların, hava araçların ve hava taşımacılığı kapsamına giren teknik altyapının herhangi bir şekilde sabotaj ve terörist saldırılar ve bunlara benzer suç unsuru taşıyan ve kasıtlı olarak eyleme dönüşmüş tehlikelerden korunması ile ilgili faaliyetleri ve bunun için gerekli olan kaynakları kapsayan kavramdır (Gerede, 2006, s. 31).

Havayolu taşımacılığı; yolcu, yük ve postanın ticari bir amaçla tarifeli ve tarifesiz olarak hava araçlarıyla taşınmasına denir (aktaran Sarılgan, 2011, s. 70). 
Taşımacılık; belirli bir bedel karşıllı̆ında müşterilerin ihtiyaçlarını karşılamak için yüklemesi yapılan malzemenin belirli bir bölgeye ulaştırılmasına denir (Erturgut, 2016, s. 115-116).

Hava taşımacılığı; bir hava aracı ile insanların, kargonun ve postanın yer faydası sağlayacak biçimde yer değiştirmesine denir. Yapılan uçuşların tamamı ticari ve kar amaçlı olmamakla beraber kişisel amaçlı uçuşlarda gerçekleşmektedir. Havacılık faaliyetleri kapsamında değerlendirilen hava taşımacılığı genellikle insanların ve yükün yer ve zaman faydası yaratacak șekilde yer değişimine odaklanır. Havacılık faaliyetler ise hem sivil hem de askeri havacılık faaliyetleri olarak değerlendirilmektedir (Gerede, 2002, s. 13-14).

Hava taşımacılı̆̆ faaliyetleri ise kendi içerisinde; genel havacılık ve havayolu taşımacılığı olarak iki gruba ayrılmaktadır (Gerede, 2002, s.4). Uluslararası Sivil Havacılık Örgütü (International Civil Aviation Organization - ICAO)'ne göre sivil havacılık faaliyetleri dokuz başlık altında sınıflandırılmaktadır. Bunlar (ICA0,2009, s. 4);

> Ticari hava taşımacılık faaliyetleri; tarifeli hava taşımacılık faaliyetleri (yolcu, kargo ve posta); tarifesiz (Charter) hava taşımacılık faaliyetleri, (yolcu, kargo ve posta)

$>$ Genel havacillk faaliyetleri,

$>$ Havalimanı faaliyetleri,

$>$ Hava seyrüsefer faaliyetleri,

$>$ Sivil hava aracı üretimi,

$>$ Havacılık eğitimleri,

$>$ Bakım onarım faaliyetleri,

$>$ Düzenleme ve işletim faaliyetleri,

$>$ Diğer hizmetler.

Hava taşımacılığı sınıflandırılması iki önemli bileşenden oluşmaktadır. Bunlar; havayolu taşımacılığı (ticari) ve genel havacılık faaliyetleridir.

Havayolu taşımacılığını ve genel havacılık faaliyetlerini, birbirinden ayıran bazı unsurlar mevcuttur. Havayolu taşımacılığı yapan işletmeler kar amacı gütmektedir. Ancak genel havacılıkta bu durum her zaman geçerli olmamaktadır. Havayolu taşımacılığında kullanılan hava araçlarının; yani uçakların taşıma kapasiteleri ve menzilleri daha fazla, hızlı, büyük ve sabit kanatlı, maksimum kalkış kapasitesi daha fazladır. Buna rağmen genel havacılıkta kullanılan hava araçları; balon yamaç paraşütü, mikro jetler ve benzerleridir. İşlevsel farklılık açısından havayolu taşımacılığında hızlı bir şekilde yer değiştirme faydası sağlanırken genel havacılıkta, uçuş eğitimi, fotoğraf çekimi, ilaçlama ve benzeri faaliyetler sağlanmaktadır. Ölçekleri açısında farklılıklar ise; havayolu taşımacılığının vermiş olduğu hizmet alanı genel havacılığa kıyasla daha büyük ve geniştir. Kamuya açıklık açısından değerlendirildiğinde ise havayolu taşımacılığı ile ücretini ödemek koşulu ile daha fazla yük ve insan taşınmaktadır. Genel havacılıkta ise bu durum kısitlıdır (Gerede, 2002, s.4).

Taşımacılık, hava taşımacılığı ve havayolu taşımacılığı kavramları üzerine yapılan açıklamalar; hava lojistiğinin daha çok havayolu taşımacılığında gerçekleşen lojistik faaliyetler olduğunu göstermektedir. Hava taşımacılığı sistemi içerisinde bulunan diğer hizmet sağlayıcılar ise hava lojistiği faaliyetlerine katkı sunmaktadır.

Hava lojistiği üzerine yapılmış akademik çalışmaların literatür taraması Tablo 1 'de verilmiștir. 


\begin{tabular}{|c|c|c|c|c|}
\hline Yil & Yazarlar & Yöntem & Ele Alınan Kriterler & Konu \\
\hline 2002 & Tsai ve $\mathrm{Su}$ & AHP & Mikro ve Makro Faktörler & $\begin{array}{l}\text { Hava Lojistiği Hub } \\
\text { Noktasının Politik } \\
\text { Risk } \\
\text { Değerlendirmesi }\end{array}$ \\
\hline 2011 & $\begin{array}{l}\text { Wen, Tsai } \\
\text { ve Lin }\end{array}$ & $\begin{array}{l}\text { Faktör Analizi } \\
\text { ve Kümeleme } \\
\text { Analizi }\end{array}$ & $\begin{array}{l}\text { Hizmet Maliyeti, Teslimat, } \\
\text { Sorumluluk, Bilgi, Algılanan Yetenek }\end{array}$ & $\begin{array}{l}\text { Dış Kaynak } \\
\text { Kullanımı }\end{array}$ \\
\hline 2011 & $\begin{array}{l}\text { Zhu ve } \\
\text { Yang }\end{array}$ & $\begin{array}{l}\text { Granger } \\
\text { Nedensellik } \\
\text { Analizi }\end{array}$ & $\begin{array}{l}\text { Hava Kargo Toplamı, İhracat İthalat } \\
\text { Toplamı }\end{array}$ & $\begin{array}{l}\text { Shanghai Hava } \\
\text { Lojistiği ile } \\
\text { Uluslararası Ticaret } \\
\text { Arasındaki İlişki } \\
\text { Çalıșması }\end{array}$ \\
\hline 2012 & $\begin{array}{l}\text { Norin ve } \\
\text { diğerleri. }\end{array}$ & $\begin{array}{l}\text { Optimizasyon } \\
\text { Modellemesi - } \\
\text { Sezgisel } \\
\text { Yöntemler }\end{array}$ & $\begin{array}{l}\text { Teker Koyma, Taksi, Kapı açma, } \\
\text { Yolcu ve bagaj İndirme, Su Alma, } \\
\text { Yakıt Alma, İkram Alma, Yolcu ve } \\
\text { Bagaj Yükleme, Sağlık Hizmetleri, } \\
\text { De-Icing İşlemleri, Uçağın İtilmesi, } \\
\text { Taksi ve Kalkış. }\end{array}$ & $\begin{array}{l}\text { Havaalanı Lojistiği - } \\
\text { Uçağın Geri Dönüş̧ } \\
\text { Operasyonunun } \\
\text { Simülasyonu }\end{array}$ \\
\hline 2012 & Zhao & $\begin{array}{l}\text { Bulut Bileşim } \\
\text { Modeli }\end{array}$ & $\begin{array}{l}\text { Altyapı hizmetleri, Sistem Sunumu, } \\
\text { Yazılım Hizmeti - Hava Kargo } \\
\text { Acentalarına, Taşımacılık } \\
\text { İşletmelerine, Havaalanı Kargo } \\
\text { İstasyonuna, Havayoluna Bulut } \\
\text { Hizmet Sağlayıcılarına }\end{array}$ & $\begin{array}{l}\text { Bulut Hesaplamaya } \\
\text { Dayalı Hava Lojistik } \\
\text { Hizmet Zincirinin } \\
\text { İşbirliği Sisteminin } \\
\text { Oluşturulması }\end{array}$ \\
\hline 2014 & Xiong & ISM & $\begin{array}{l}\text { Havacılık Lojistiği Teknik Bilgisi, } \\
\text { Profesyonellerin Eksikliği, Navlun } \\
\text { Piyasasının Yapısı, Havacılık } \\
\text { Lojistiği Bilgisi, Altyapı, Modern } \\
\text { Lojistik Seviyesi, Hava Lojistik } \\
\text { Servis Platformu, Yönetim Seviyesi, } \\
\text { Tüketici Bilinci, Politikalar Ve } \\
\text { Düzenlemeler, Havacılık Lojistiğinin } \\
\text { Gelișim Düzeyi }\end{array}$ & $\begin{array}{l}\text { Havacılık Lojistiği } \\
\text { Merkezi Alanlarının } \\
\text { Geliştirilmesi } \\
\text { Üzerine Bir Çalışma: } \\
\text { Zhengzhou } \\
\text { Uluslararası } \\
\text { Havalimanı }\end{array}$ \\
\hline 2014 & $\begin{array}{l}\text { Wang ve } \\
\text { Liu }\end{array}$ & İş Modeli & $\begin{array}{l}\text { Verilen Değer, Hedef Müșteri Grubu, } \\
\text { Dağıtım Kanalları, Müșteri İlișkileri, } \\
\text { Değer İnşası, Çekirdek Yetenekler, } \\
\text { Ortaklıklar Ağı, Maliyet Yapısı, Gelir } \\
\text { Modellemesi }\end{array}$ & $\begin{array}{l}\text { Çin Havacılık } \\
\text { Lojistik } \\
\text { İşletmelerinin } \\
\text { Gelişimi Hakkında } \\
\text { Bir İnceleme } \\
\end{array}$ \\
\hline 2014 & $\begin{array}{l}\text { Zhang ve } \\
\text { diğerleri. }\end{array}$ & MCAHR & A320 tipi Uçakların Tarihsel Verileri & $\begin{array}{l}\text { Uçak Yedek Parçası } \\
\text { Tahmin Modeli }\end{array}$ \\
\hline 2015 & Zhou & Elmas Model & $\begin{array}{l}\text { Ekonomik Rekabet Gücü, Havacılık } \\
\text { Lojistiğinin Mesleki Yeteneği, } \\
\text { Altyapı İnșası, Hükümetin Yönetim } \\
\text { Kapasitesi }\end{array}$ & $\begin{array}{l}\text { Zhengzhou } \\
\text { Havaalanı Havacılık } \\
\text { Lojistiği } \\
\text { Endüstrisinin } \\
\text { Değerlendirmesi } \\
\end{array}$ \\
\hline 2015 & Wang & $\begin{array}{l}\text { Literatür } \\
\text { Analizi }\end{array}$ & $\begin{array}{l}\text { Çin havacılık Lojistği Endüstrisinin } \\
\text { Durumu, Havacılık Lojistiğinin } \\
\text { Temel Kavramları, Havacılık } \\
\text { Lojistiğinin Gelecekteki Gelişimi }\end{array}$ & $\begin{array}{l}\text { Çin'de Havacılık } \\
\text { Lojistiği } \\
\text { Endüstrisinin } \\
\text { Geliştirilmesi } \\
\text { Çalışması } \\
\end{array}$ \\
\hline 2018 & $\begin{array}{l}\text { Wu ve } \\
\text { Yang }\end{array}$ & $\begin{array}{l}\text { Hibrit Veri } \\
\text { Madenciliği } \\
\text { Modeli }\end{array}$ & $\begin{array}{l}\text { Pist Genişliği, Hava Kargo } \\
\text { Platformu, Özel Lojistik ve } \\
\text { Belgelendirme, E-Ticaret Lojistiği, } \\
\text { İşbirliği, Ağ Genişlemesi, Pazar } \\
\text { Gözlemi ve Uçak Dönüşümü }\end{array}$ & $\begin{array}{l}\text { Hava Kargo Lojistik } \\
\text { Yönetimi için } \\
\text { Yapılmış Büyük Veri } \\
\text { Analitiği }\end{array}$ \\
\hline
\end{tabular}

Tablo 1: Hava Lojistiği Alanında Yapılmıș Çalışmalar 


\section{Bibliyometri}

Bibliyometri, dil bilgisi açısından iki sözcügün birleşmesiyle oluşmuştur. Latince ve Yunanca'da kitap anlamına gelen "biblion" kelimesinden "biblio" kelimesi türetilmiştir. Bununla beraber ölçü birimi olarak ifade edilen "metrics" kelimesi ise; Latince ve Yunanca'da kullanılan "metricus" or "metrikos" yani ölçü anlamına gelen kelimeden türetilmiştir. Bu iki kelimenin birleșmesi ile bibliyometri kavramı oluşturulmuştur (Sengupta, 1992, s,75). Pritchard (1969) bibliyometriyi, matematiksel ve istatiksel yöntemlerin iletişim araçlarına ve kitaplara uygulanması; Broadus (1987), analizde kullanılan bibliyografik bilgilerin nicelendirilmesi ve fiziksel olarak yayınlanmış kaynakların veya bibliyografik bilgilerin kaynaklarının niceleyici olarak çalışılması; Hood ve Wilson (2001) ise bibliyometriyi, bir disiplinin gelişim sürecinin ve doğasının ve yazılı iletişim süreçlerinin aydınlatılması șeklinde ifade etmiştir.

Bibliyometrik analiz, bibliyografik materyalin kantitatif olarak değerlendirilmesidir. Bu yöntem makalelerin, yazarların ve dergilerin sınıflandırılarak bir araştırma alanının görsel olarak betimlenmesini sağlamaktadır (Merigo ve Yang, 2017, s.37). Bibliyometrik teknikler, zaman içerisinde önemli bir yere gelmiștir. Kullanılan bu tekniklerle bir ülke, kurum veya bir yazarın ortaya koyduğu katkıların analizinin yapılması ve yapılan yayınların bilimsel alana olan katkısının belirlenmesi, aynı yayında olan bir kaynağa yapılan atıfların sayısının belirlenmesi şeklinde analiz teknikleri ortaya çlkmıştır (Okuba, 1997, s. 8-9). Koehler (2001:120) bibliyometrik yöntemler üzerine çalışan kişilerin çalışmalarını kendi içerisinde dört gruba ayırmıştır. Bunlar:

$>$ Atıf analizleri yapan araştırmacılar. Bireyler, kurum ve kuruluşlar, bilimsel disiplinler ve bazı tek eserli çalışmalar üzerine yapılan araştırmalar.

$>$ Ortak atıf analizleri yapan araștırmacılar. Bireyleri, ülkeleri, beyin göçünü, düşünce okullarını görselleştirmek için atıf analizlerine odaklanırlar.

$>$ Kişilerin, kurumların veya ülkelerin verimliliği üzerine yapılan çalışmalar.

$>$ Bilgi ürünleri üzerine çalışanlar. Yazarlar, kitaplar, patent ve diğer konular üzerine araștırma yapanlardır.

Bibliyometrik analiz yöntemleri kullanılarak yapılan bazı çalışmalar literatürden verilmiştir. Leung, ve diğerleri (2017) sosyal medya araştırmaları üzerine akademik literatürün ortak atıf ve ortak kelime analizi ile sistematik ve bütünsel incelenmesini; Benckendorff ve Zehrer (2013) turizmle ilgili önde gelen makaleleri ve yazarları ortak atıf ve ağ analizini kullanarak; Zhao ve diğerleri (2018) uluslararası işletme dergisinde kurumsal kaynak yönetimi üzerine ortak atıf analizini; Merigo ve Yang (2017) yöneylem araştırması ve yöneylem biliminin bibliyometrik olarak incelenmesini; Yu ve Xu (2017) karbon emisyon ticareti üzerine konu, dergi, ülke, yazar vb ölçütleri ortak atıf analizi ile; Zhou ve diğerleri (2018) enerji güvenliği üzerine ortak analizi yöntemini; Hallinger ve Wang (2020) yönetim eğitiminde simülasyona dayalı öğrenmenin kullanımını araștırmak üzere ortak atıf çalışması ve eş kelime analizi üzerine; Raza ve diğerleri (2020) ortak atıf analizi yöntemi ile havayolu endüstrisinde gelir yönetimi konusunda vb. çalışmıştır.

\section{Yöntem}

Bu çalışma, hava lojistiği üzerine yapılmış akademik çalışmaların geçmişten günümüze değişimlerini belirlemek amacıyla yapılmıştır. Araştırmanın amacına ulaşabilmek için kaynakların niteliklerini tespit etmek üzere; matematiksel ve istatiksel yöntemlerin dokümanlara uygulanması olan bibliyometrik analiz yöntemi kullanılmıştır (Lawani, 1981, s. 294; Pritchard, 1969, s.348). 
Web of Science Core Collection, Scopus, Ebscho Academic Search Complete'te hava lojistiği ile ilgili kısıtlar belirlenerek tarama yapılmıştır. Söz konusu kısıtlar; 26.04.2019 tarihinde Web of Science Core Collection, Scopus, Ebscho Academic Search Complete'de tüm yılları kapsayan tam metin olarak erişime açı akademik yayınları, yayınların İngilizce dilinde olmasını, anahtar kelimelerin başlıklarda kullanılmasını ve makalelerin vaka çalışması olmaması özelliklerine göre belirlenmiştir. Araştırma kapsamında başlıkta (tittle) taramaya tutulan kelimeler; "cargo airlines" or "cargo aircraft" or "freight tonne kilometes" or "airport freight" or "ground handling" or "air freight" or "airfreight" or "air freight cargo" or "air cargo" or "airport cargo" or "air cargo transportation" or "airline cargo transportation" or "air cargo transportation" or" air supply chain" or "air cargo supply chain" or "aviation supply chain" or "air logistics" or "airport logistics" or "aviation logistics" or "air cargo logistics" or "airline logistics" or "aviational logistics" or "airway logistics" or "aerodrome logistics" or "airdrome logistics" or "drome logistics"ten oluşmaktadır. Bu sınırlılıklarla yapılan araştırmada sonuçların hava lojistiği konusu ile ilgili olarak ortaya çıkmasının garanti altına alınmasına çalışılmıştır.

Yapılan taramalar sonucunda Web of Science Core Collection'da konu ile alakalı 14 makaleye ulaşılmış ve bu makalelerin sadece 4 tanesinin "hava lojistiği" konusu için bibliyometrik çalıșmalarda kullanılmak üzere uygun olduğu gözlemlenmiştir. Scopus veri tabanında yukarıdaki anahtar kelimeler taranmış olup bu anahtar kelimelerin erişime açılk makalelerle eșleşmesi sonucunda toplam 33 makaleye ulaşılmıştır. Bu makalelerden 9 tanesi bibliyometrik analiz için uygun görülmüștür. EBSCO'da yukarıdaki anahtar kelimeler taranmış olup makalelerin diğer dergilerde aranan şartlar ile aynı koşullarda olması kısıtı ile toplamda hava lojistiği ile ilişkili 39 makaleye ulaşılmış; ancak bu veri setinden bibliyometrik çalışma için 13 makale uygun görülmüştür. Her üç veri tabanı incelendiğinde hava lojistiği ile ilgili betimsel ve değerlendirici bibliyometrik analiz çalışması için 26 makale incelemeye alınmıştır. Çalışma konusu ile ilgili olan yazarlar, anahtar kelimeler, atıflar, kaynakça atıfları, dergiler ve diğer alt faktörler, Excel üzerinde görselleştirilmiş, tablolaştırılmış ve analiz edilmiştir. Belirlenen kısıtlar çerçevesinde elde edilen veriler (Tablo 6) analiz edilerek en iyi sonuçların bulunulacağı varsayılmıştır.

\section{Bulgular}

Scopus, WOS ve EBSCO'da taranan hava lojistiği ile ilgili 26 erişime açık makalede en çok çalışılan disiplinler; "Yöneylem Araştırmaları, Mühendislik Bilimleri, Ekonomi, Pazarlama, Çevre Bilimi, Tedarik Zinciri, Coğrafya, Küreselleşme, Bilgi Teknolojileri, Hukuk, İstatistik" olarak gözlenmiştir. Belirli bir zaman aralığında yazılmasına bakılmaksızın yöntem kısmında ifade edilen kısıtlarla yapılan hava lojistiği ile ilgili bibliyometrik araştırmada incelenen 26 makalenin en sık işlendiği yıl, 2013 yılıdır. 


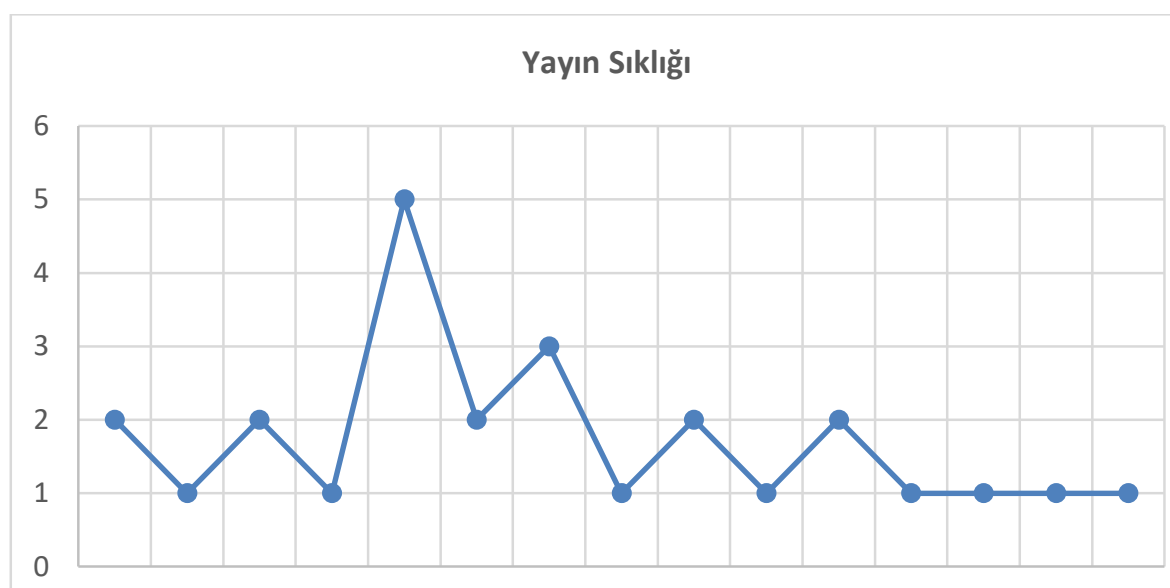

201820172016201520132012200920082007200520042003200219991997

Şekil 2. Hava Lojistiği İle İlgili Yıllara Göre Yayın Sayıları

Şekil 2 incelendiğinde hava lojistiği üzerine yapılan yayınların 2003 yılından 2014 yılına kadar artan eğilim içinde olduğu gözlenmektedir. Ancak 2015 yılından itibaren hava lojistiği ile ilgili çalışmalar azalmaya başlamıştır.

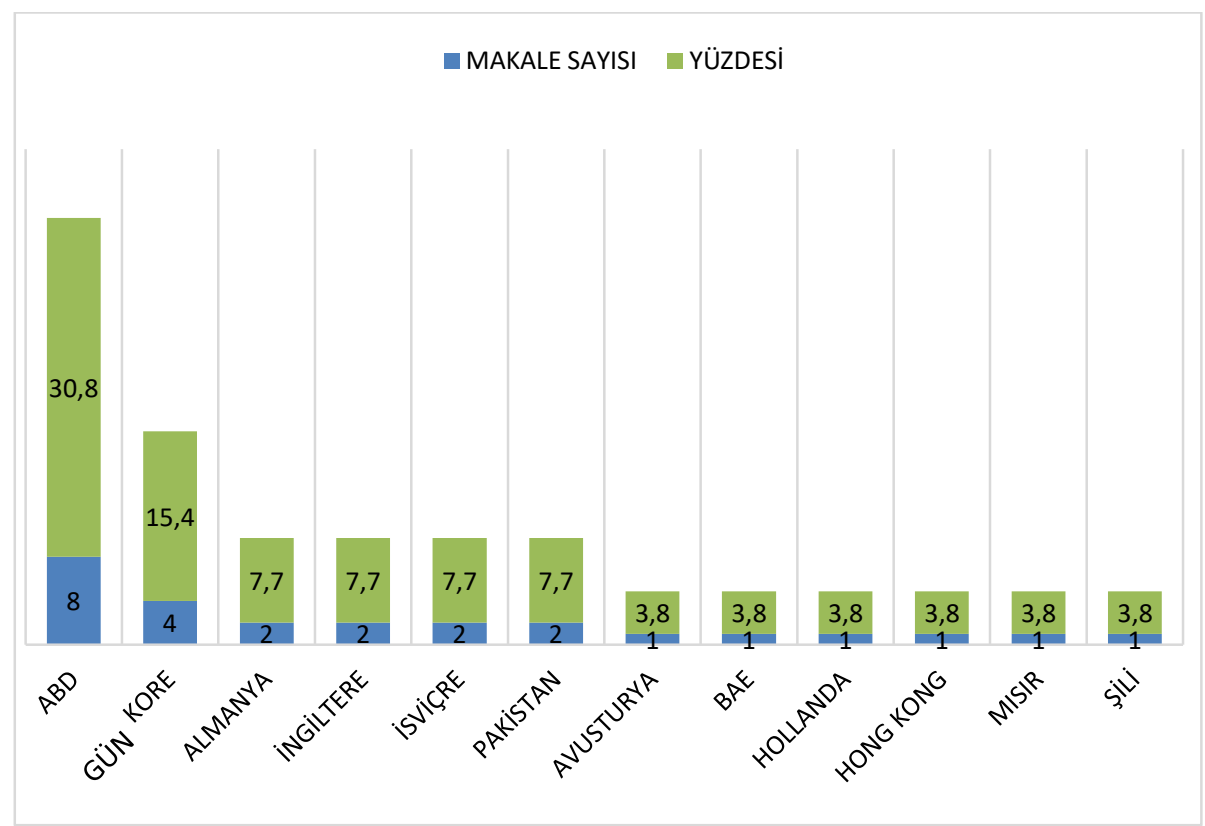

Şekil 3. Makalelerin Yayınlandığı Ülkeler ve Yüzdesi

Şekil 3'te hava lojistiği ile ilgili bilimsel yayınların yürütüldüğü ülkeler ve bu ülkelerdeki yayınların yüzdesel oranı gösterilmektedir. Bu bağlamda hava lojistiği üzerine yapılan çalıșmaların büyük çoğunluğu ABD'de yayınlanmıștır. 26 Makalenin 8 
tanesi yani tamamının \%31'i ABD'de yayınlanmış olup ABD'yi hava lojistiği konusu ile ilgili yayınlarda Güney Kore takip etmektedir.

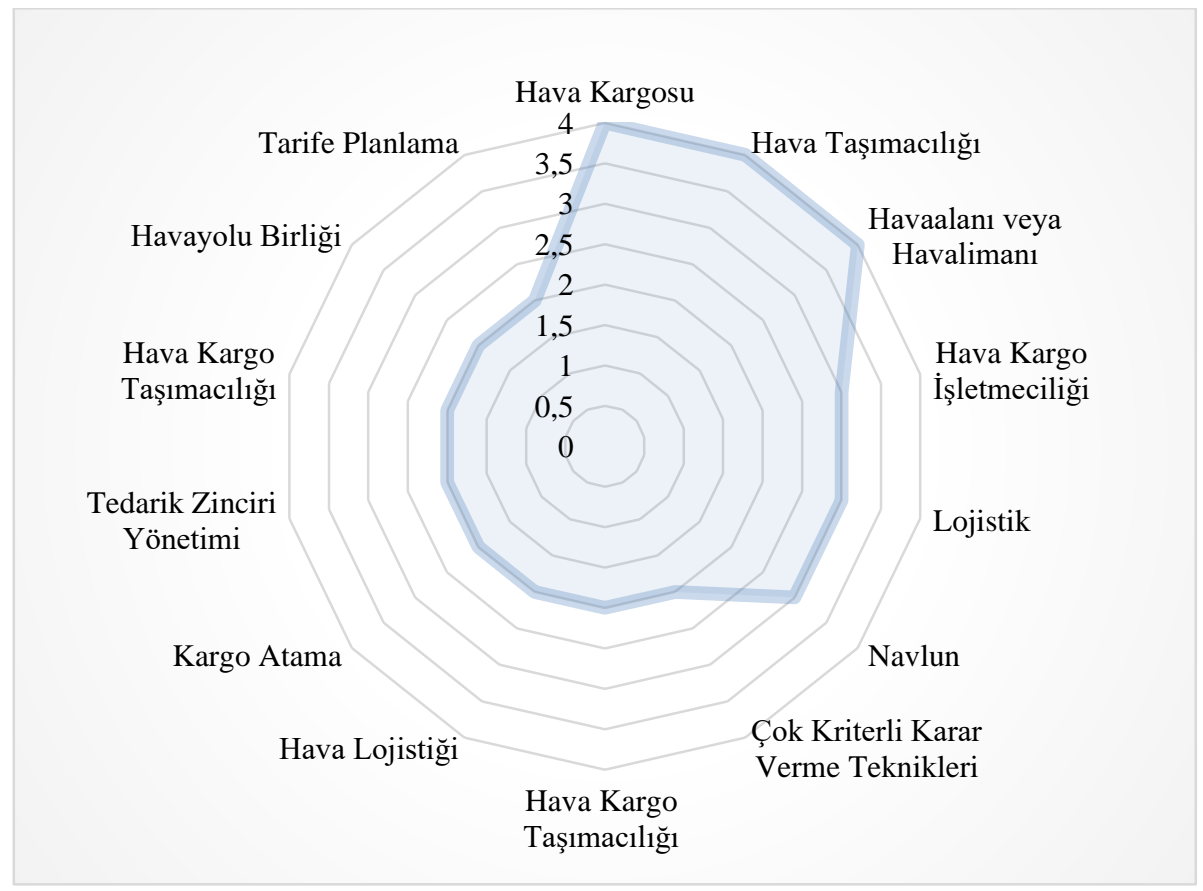

Şekil 4. Makalelerde En Sık Kullanılan Anahtar Kelimeler

Hava lojistiği üzerine yazılan makalelerdeki anahtar kelimelerin yoğunluğu incelendiğinde, alan ile ilgili en çok kullanılan anahtar kelimeler; hava kargosu, hava taşımacılığı, havalimanı, hava kargo işletmeciliği, lojistik ve navlundur. Burada hava lojistiği ile ilgili yapılan çalışmalarda hava kargosunun hava lojistiği içeresinde büyük bir yer kapladığı görülmektedir. 


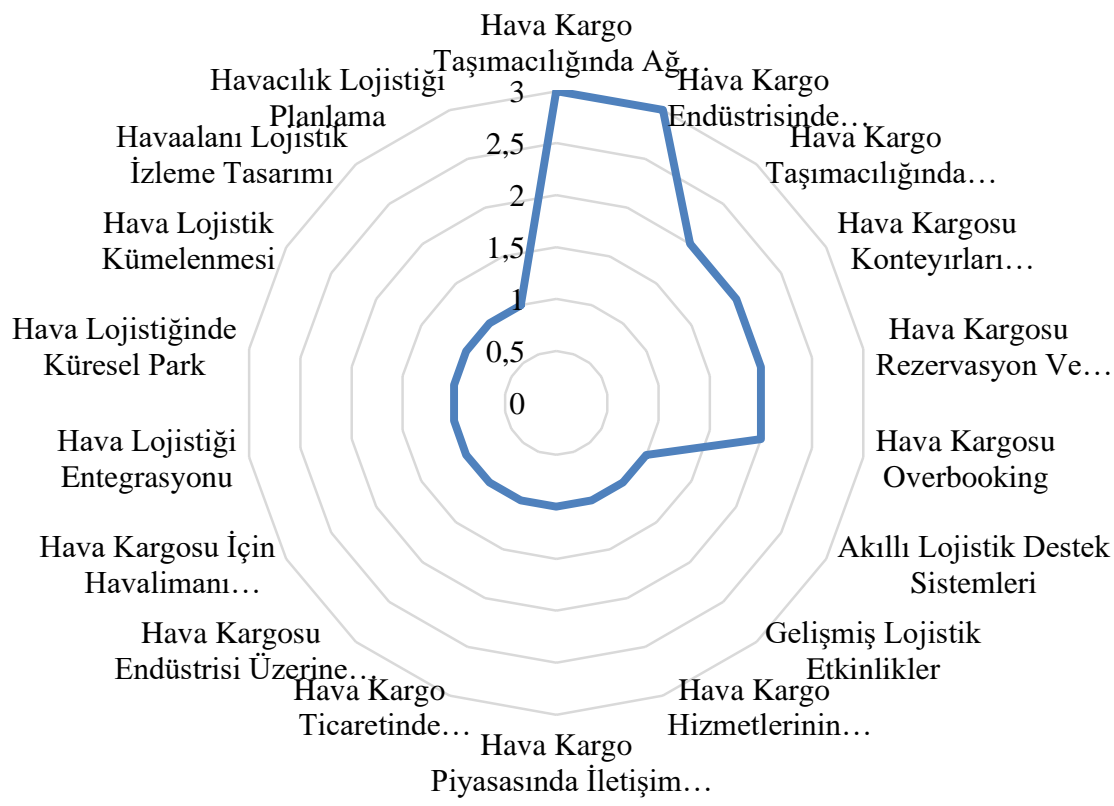

Şekil 5. Havacılık Lojistiği Üzerine Yapılan Çalışmaların Konusu ve Sıklığı

Hava lojistiği üzerine yapılan akademik çalışmaların konusuna göre dağılımı Şekil 5 'de görselleștirilmiştir. Yapılan analizlere göre hava lojistiği ile ilgili en çok hava kargo tașımacılığında ağ tasarımı modelleri ve hava kargo endüstrisinde sürdürülebilir rekabet çalıșmaları yapılmıştır. Şekil 5 incelendiğinde hava lojistiği ile ilgili en az çalışılan konular aşağıda verilmiştir.

- Hava lojistik kümelenmesi,

- Hava lojistiğinde küresel park,

- Hava lojistiği entegrasyonu,

- Hava kargosu için alternatif meydan seçimi,

- Hava kargosu üzerine elektronik düzenlemeler ve diğerleri.

SCImago Dergisi \& Ülke Sıralaması (SCImago Journal \& Country Rank-SJR); Scopus ve Elsevier BV veri tabanından akademik yayınlarla ilgili almış olduğu bilgileri analiz ederek dergiler ve ülkelerle ilgili elde edilen bilgilerin sonuçlarını araştırmacılara sunan bir portaldır. Bu portaldaki göstergeler, bilimsel tabloları değerlendirmek ve analiz etmek için sunulmaktadır. (SCImago, 2019). 


\begin{tabular}{|l|l|l|}
\hline Dergiler & Adet & SJR Etki Faktörü \\
\hline Transportation Science & 2 & 3,312 \\
\hline Or Spectrum & 1 & 1,232 \\
\hline International Transactions Inoperatıonal Research & 1 & 1,071 \\
\hline Computers and Mathematics With Applications & 1 & 1,058 \\
\hline Journal of Air Transportation & 1 & 0,981 \\
\hline Applied Mathematical Modelling & 1 & 0,876 \\
\hline The Information Society An International Journal & 1 & 0,741 \\
\hline Papers in Regional Science & 1 & 0,732 \\
\hline Transportation Journal & 3 & 0,637 \\
\hline Geografiska Annaler: Series B, Human Geography & 1 & 0,618 \\
\hline Sustainability & 1 & 0,537 \\
\hline Expert Systems & 1 & 0,429 \\
\hline Asian Journal of Shipping And Logistics & 3 & 0,389 \\
\hline The Asian Journal of Shipping And Logistics & 2 & 0,389 \\
\hline Ingeniare & 1 & 0,239 \\
\hline Journal of Applied Mathematics & 1 & 0,218 \\
\hline International Journal of Online and Biomedical Engineering & 1 & 0,181 \\
\hline Sae International Journal of Aerospace & 1 & 0,18 \\
\hline Information Technology Journal & 1 & 0,11 \\
\hline Journal of Applied Sciences & 1 & 0,101 \\
\hline Toplam & 26 & \\
\hline
\end{tabular}

Tablo 2: Yayınların Yer Aldığı Dergiler ve Etki Faktörleri -2017

Tablo 2, SCImago Journal Rank (SJR) indeksi referans alınarak hava lojistiği ile ilgili yayınlanmıș 26 makalenin etki faktörü dikkate alınarak hazırlanmıștır. SJR indeksine göre hava lojistiği ile ilgili en etkili dergi, Transportation Science'tır. Ele alınan 26 makaleden sadece " 2 " tanesi bu dergide yayınlanmıștır. Bu sayı da erişime açı 26 makalenin \%8'ne karşılık gelmektedir. Bu dergiyi SJR etki faktörü sıralamasında; OR Spectrum, Journal of Air Transportation, Applied Mathematical Modelling ve diğerleri izlemektedir.

\begin{tabular}{|l|l|l|}
\hline Veri Tabanları ve İndeksler (EBSCO) & Siklık & Yüzde \\
\hline Scopus & 22 & 84 \\
\hline Academic Search Complete & 17 & 65 \\
\hline Business Source Complete & 11 & 42 \\
\hline SSCI & 10 & 38 \\
\hline Complementary Index & 10 & 38 \\
\hline Academic Onefile & 10 & 38 \\
\hline Sciencedirect & 6 & 33 \\
\hline Supplemental İndex & 5 & 19 \\
\hline Jstor Journals & 4 & 16 \\
\hline Directory of Open Access Journals & 4 & 16 \\
\hline General Onefile & 2 & 8 \\
\hline Expanded Academic Asap & 2 & 8 \\
\hline Infotrac Newsstand & 1 & 4 \\
\hline Applied Science \& Business Periodicals & 1 & 4 \\
\hline Retrospective: 1913-1983 (H.W. Wilson) & 1 & 4 \\
\hline Econis & 1 & 4 \\
\hline Masterfile Complete & 1 & 4 \\
\hline Oaister & 1 & 4 \\
\hline
\end{tabular}

Tablo 3: Hava Lojistiği Üzerine Yazılmış Makalelerin Sağlandığı İndeksler ve Veri Tabanları 
Tablo 3'te hava lojistiği alan yazınında taranan 26 makalenin veri tabanlarındaki ve indekslerdeki sıklığı ile yüzdesel dağılımı gösterilmektedir. Hava lojistiği ile ilgili araştırılan makalelerin önemli bir kısmı Scopus veri tabanında taranmaktadır. Scopus'ta hava lojistiği ile ilgili 26 makalenin 22'si taranmaktadır. Bu sayı yüzdelik dilimde 26 makalenin yüzde 84'ünü ifade etmektedir. SSCI indeksinde taranan 10 makalenin yüzdesel karşılığı ise \%38'dir.

\begin{tabular}{|l|l|l|l|l|}
\hline Sıra & Makale & Yazar/Yıl & GA-Atıf & Yazar Sayıs \\
\hline 1 & Single-Leg Air-Cargo Revenue Management & $\begin{array}{l}\text { Amaruchkul ve } \\
\text { diğerleri: } 2007\end{array}$ & 112 & 3 \\
\hline 2 & $\begin{array}{l}\text { The Capacitated P-Hub Median Problem With } \\
\text { Integral Constraints: An Application to a } \\
\text { Chinese Air Cargo Network }\end{array}$ & $\begin{array}{l}\text { Lin ve diğerleri: } \\
2012\end{array}$ & 58 & 3 \\
\hline 3 & $\begin{array}{l}\text { Core Competencies And Sustainable } \\
\text { Competitive Advantage in Air-Cargo } \\
\text { Forwarding: Evidence from Taiwan }\end{array}$ & $\begin{array}{l}\text { Chen ve Yeh: } \\
2017\end{array}$ & 45 & 2 \\
\hline 4 & $\begin{array}{l}\text { The Air Cargo Industry in China: Implications } \\
\text { of Globalization and WTO Accession }\end{array}$ & $\begin{array}{l}\text { Fung ve } \\
\text { diğerleri: } 2005\end{array}$ & 40 & 4 \\
\hline 5 & $\begin{array}{l}\text { Air Cargo Services in Asian Industrialising } \\
\text { Economies: Electronics Manufacturers and The } \\
\text { Strategic Use of Advanced Producer Services }\end{array}$ & $\begin{array}{l}\text { Bowen ve } \\
\text { Leinbach: } 2003\end{array}$ & 37 & 2 \\
\hline 6 & $\begin{array}{l}\text { An Intelligent Logistics Support System for } \\
\text { Enhancing the Airfreight Forwarding Business }\end{array}$ & $\begin{array}{l}\text { Lau ve diğerleri: } \\
2004\end{array}$ & 31 & 5 \\
\hline 7 & $\begin{array}{l}\text { An Application of A Fuzzy Knowledge System } \\
\text { for Air Cargo Overbooking Under Uncertain } \\
\text { Capacity }\end{array}$ & $\begin{array}{l}\text { Wang ve Kao: } \\
2008\end{array}$ & 29 & 2 \\
\hline 8 & $\begin{array}{l}\text { A Mixed Integer Programming Formulation for } \\
\text { the Three-Dimensional Bin Packing Problem } \\
\text { Deriving from an Air Cargo Application }\end{array}$ & $\begin{array}{l}\text { Paquay ve } \\
\text { diğerleri: } 2016\end{array}$ & 28 & 2 \\
\hline 9 & $\begin{array}{l}\text { A New Approach for Air Cargo Network } \\
\text { Planning }\end{array}$ & $\begin{array}{l}\text { Derigs ve } \\
\text { diğerleri: } 2009\end{array}$ & 23 & 3 \\
\hline 10 & $\begin{array}{l}\text { Hlobal Transpark: New Competitiveness for } \\
\text { Logistics }\end{array}$ & Sit: 2004 & 15 & 27 \\
\hline 10 Makalenin Toplamı & 26 Makalenin Genel Toplam & 489 & 57 \\
\hline
\end{tabular}

Tablo 4: Yayınlara Yapılan Atıf ve Yayınların Yazar Sayısı (En Çok Atıf Alan 10 Makale)

Tablo 4'teki hava lojistiği ile ilgili taranan 26 makalenin ve yazarın aldığı atıflara göre ilk 10 sıralaması verilmiștir. Bu 10 makalenin aldığı toplam atıf sayısı 418 olmakla beraber en çok atıf alan yazar Amaruchkul ve diğerleridir. Atıflar Google Akademik üzerinden derlenmiştir. 


\begin{tabular}{|c|c|c|c|c|}
\hline Sira & Makale & Yazar/Yıl & Türü & Atıf \\
\hline 1 & $\begin{array}{l}\text { Issues on Liberalization of Air Cargo Services in } \\
\text { International Aviation }\end{array}$ & $\begin{array}{l}\text { Zhang ve } \\
\text { Zhang: } 2002 a\end{array}$ & Makale & 3 \\
\hline 2 & $\begin{array}{l}\text { A Conceptual Model of Service Quality and Its } \\
\text { Implications For Future Research }\end{array}$ & $\begin{array}{l}\text { Parasuraman } \\
\text { ve diğerleri: } \\
1985\end{array}$ & Makale & 2 \\
\hline 3 & $\begin{array}{l}\text { A Gap Analysis in Service Quality for Air Freight } \\
\text { Forwarders }\end{array}$ & Hsu:2011 & Makale & 2 \\
\hline 4 & $\begin{array}{l}\text { A Model of Air Cargo Liberalization: Passenger } \\
\text { vs. All-Cargo Carriers }\end{array}$ & $\begin{array}{l}\text { Zhang ve } \\
\text { Zhang: } 2002 b\end{array}$ & Makale & 2 \\
\hline 5 & $\begin{array}{l}\text { A study of the Competitiveness of Airline Cargo } \\
\text { Services Departing From Korea: Focusing on the } \\
\text { Main Export Routes }\end{array}$ & $\begin{array}{l}\text { Yoon ve Park: } \\
2015\end{array}$ & Makale & 2 \\
\hline 6 & $\begin{array}{l}\text { An Assessment of Knowledge Gap in Service } \\
\text { Quality for Air Freight Carriers }\end{array}$ & $\begin{array}{l}\text { Huang ve } \\
\text { diğerleri: } 2016\end{array}$ & Makale & 2 \\
\hline 7 & $\begin{array}{l}\text { An Economic Model for Air Cargo Overbooking } \\
\text { Under Stochastic Capacity }\end{array}$ & $\begin{array}{l}\text { Kasilingam, R. } \\
\text { G.: } 1997\end{array}$ & Makale & 2 \\
\hline 8 & $\begin{array}{l}\text { An Experimental Application of the Delphi } \\
\text { Method to the Use of Experts }\end{array}$ & $\begin{array}{l}\text { Dalkey ve } \\
\text { Helmer: } 1963\end{array}$ & Makale & 2 \\
\hline 9 & $\begin{array}{l}\text { Condorcet: Foundations of Social Choice and } \\
\text { Political Theory }\end{array}$ & $\begin{array}{l}\text { McLean ve } \\
\text { Hewitt: (1994) }\end{array}$ & Kitap & 2 \\
\hline 10 & $\begin{array}{l}\text { Criteria for Services of Air Cargo Logistics } \\
\text { Providers: How Do They Relate to Client } \\
\text { Satisfaction? }\end{array}$ & $\begin{array}{l}\text { Meng ve } \\
\text { diğerleri: } 2010\end{array}$ & Makale & 2 \\
\hline
\end{tabular}

Tablo 5: 26 Makalede En Çok Referans Atıfın Yapıldığı 10 Akademik Çalışma

Tablo 5'te hava lojistiği konusu üzerine yapılmıș 26 makaleye, yapılan atıfların akademik yayın türüne ve atıf sayısına göre sıralanması verilmiştir. Hava lojistiğinde en çok atıfı "Issues On Liberalization of Air Cargo Services in International Aviation" makale çalışmasıyla Anming Zhang ve Yimin Zhang almıştır. İlk 10 yayın içerisinde sadece bir tane kitaba atıf yapılmıștır. Diğer atıfların tamamı makalelere yapılmıștır.

\begin{tabular}{|c|c|c|c|}
\hline Sira & & Yazar/Yıl & Atıf \\
\hline 1 & $\begin{array}{l}\text { Core Competencies and Sustainable Competitive Advantage } \\
\text { in Air-Cargo Forwarding: Evidence from Taiwan }\end{array}$ & $\begin{array}{l}\text { Cheng ve } \\
\text { Yeh: } 2017\end{array}$ & 53 \\
\hline 2 & $\begin{array}{l}\text { Global Transpark: New Competitiveness for Hong Kong and } \\
\text { South China Based }\end{array}$ & Sit: 2004 & 35 \\
\hline 3 & $\begin{array}{l}\text { Air cargo services in Asian industrialising economies: } \\
\text { Electronics manufacturers and the strategic use of advanced } \\
\text { producer services }\end{array}$ & $\begin{array}{l}\text { Bowen ve } \\
\text { Leinbach: } \\
2003\end{array}$ & 34 \\
\hline 4 & Structural Change in the International Advanced Logistics & $\begin{array}{l}\text { Miyashita: } \\
2009\end{array}$ & 34 \\
\hline 5 & $\begin{array}{l}\text { Evaluating competitiveness of transshipment cargo in major } \\
\text { airports in northeast Asia: Airport branding }\end{array}$ & $\begin{array}{l}\text { Chung ve } \\
\text { Han: } 2013\end{array}$ & 33 \\
\hline 6 & $\begin{array}{l}\text { A mixed integer programming formulation for the three- } \\
\text { dimensional bin packing problem deriving from an air cargo } \\
\text { application }\end{array}$ & $\begin{array}{l}\text { Paquay ve } \\
\text { diğerleri: } \\
2016 .\end{array}$ & 32 \\
\hline 7 & $\begin{array}{l}\text { Air cargo scheduling: Integrated models and solution } \\
\text { procedures }\end{array}$ & $\begin{array}{l}\text { Derigs ve } \\
\text { Friederichs: } \\
2013\end{array}$ & 31 \\
\hline
\end{tabular}




\begin{tabular}{|c|c|c|c|}
\hline 8 & Single-Leg Air-Cargo Revenue Management & $\begin{array}{l}\text { Amaruchkul } \\
\text { ve diğerleri: } \\
2007\end{array}$ & 31 \\
\hline 9 & $\begin{array}{l}\text { Analysis of the Air Transport Network Characteristics of } \\
\text { Major Airports }\end{array}$ & $\begin{array}{l}\text { Song ve Yeo: } \\
2017\end{array}$ & 29 \\
\hline 10 & $\begin{array}{l}\text { Structuring multicriteria model for airports selection for } \\
\text { cargo airlines exclusively }\end{array}$ & $\begin{array}{l}\text { De Lima ve } \\
\text { Belderrain: } \\
2016\end{array}$ & 27 \\
\hline 11 & A New Approach for Air Cargo Network Planning & $\begin{array}{l}\text { Derigs ve } \\
\text { diğerleri: } \\
2009\end{array}$ & 24 \\
\hline 12 & $\begin{array}{l}\text { The Air Cargo Industry in China: Implications of } \\
\text { Globalization and WTO Accession }\end{array}$ & $\begin{array}{l}\text { Fung ve } \\
\text { diğerleri: } \\
2005\end{array}$ & 24 \\
\hline 13 & $\begin{array}{l}\text { Improving the Sustainable Competitiveness of Service } \\
\text { Quality within Air Cargo Terminals }\end{array}$ & $\begin{array}{l}\text { Hu ve } \\
\text { diğerleri: } \\
2018 \\
\end{array}$ & 24 \\
\hline 14 & $\begin{array}{l}\text { An intelligent logistics support system for enhancing the } \\
\text { airfreight forwarding business }\end{array}$ & $\begin{array}{l}\text { Lau ve } \\
\text { diğerleri:20 } \\
04\end{array}$ & 20 \\
\hline 15 & $\begin{array}{l}\text { Dynamic Set Pair of AHP Method for Aviation Logistics } \\
\text { Planning and Research }\end{array}$ & $\begin{array}{l}\text { Tie-Jun ve } \\
\text { diğerleri: } \\
2013 \\
\end{array}$ & 20 \\
\hline 16 & $\begin{array}{l}\text { Electronic Technology and Simplification of Customs } \\
\text { Regulations and Procedures in Air Cargo Trade }\end{array}$ & Zhang: 2002 & 19 \\
\hline 17 & Lightweight Composite Air Cargo Containers & $\begin{array}{l}\text { William ve } \\
\text { diğerleri: } \\
2016\end{array}$ & 18 \\
\hline 18 & $\begin{array}{l}\text { An application of a fuzzy knowledge system for air cargo } \\
\text { overbooking under uncertain capacity }\end{array}$ & $\begin{array}{l}\text { Wang ve } \\
\text { Kao: } 2008\end{array}$ & 17 \\
\hline 19 & $\begin{array}{l}\text { The capacitated p-hub median problem with integral } \\
\text { constraints: An application to a Chinese air cargo network }\end{array}$ & $\begin{array}{l}\text { Lin ve } \\
\text { diğerleri: } \\
2012 \\
\end{array}$ & 16 \\
\hline 20 & Selling Strategy and Air Freight Decisions. & $\begin{array}{l}\text { Hulbert ve } \\
\text { Binkley: } \\
1997\end{array}$ & 13 \\
\hline 21 & $\begin{array}{l}\text { A Study on Selections of Strategic Type of Business in Air- } \\
\text { logistics Industry Clusters }\end{array}$ & Chung: 2009 & 13 \\
\hline 22 & $\begin{array}{l}\text { An Optimization Model of the Single-Leg Air Cargo Space } \\
\text { Control Based on Markov Decision Process }\end{array}$ & $\begin{array}{l}\text { Qin ve } \\
\text { diğerleri: } \\
2012\end{array}$ & 13 \\
\hline 23 & $\begin{array}{l}\text { A Framework for Electronic Coordination in the Air Cargo } \\
\text { Market }\end{array}$ & $\begin{array}{l}\text { Bodendorf: } \\
1999\end{array}$ & 10 \\
\hline 24 & $\begin{array}{l}\text { Application of Wireless Sensor Network and RFID } \\
\text { Monitoring System in Airport Logistics }\end{array}$ & Le: 2018 & 10 \\
\hline 25 & Simulation of Air Cargo Operations in West PACTL & $\begin{array}{l}\text { Danyang: } \\
2013\end{array}$ & 7 \\
\hline 26 & $\begin{array}{l}\text { Strategic Thinking on Development of Air Logistics in } \\
\text { Comprehensive Economic Experimental Community of } \\
\text { Zhengzhou Airport }\end{array}$ & $\begin{array}{l}\text { Xiao-Li: } \\
2013\end{array}$ & 5 \\
\hline
\end{tabular}

Tablo 6: Hava Lojistiği Üzerine Yazılmış 26 Makalenin Kaynak Atıf Sayısı

Tablo 6'da araştırmaya konu olan her bir makalenin kaynakçasında kaç tane akademik yayına atıf yaptığını gösteren bir çalışma mevcuttur. İlk sırayı hava kargosu ile ilgili yazılan şu makale yer almıştır: Core Competencies and Sustainable Competitive 
Advantage in Air-Cargo Forwarding: Evidence from Taiwan. Bu makaleyi sırasıyla diğerleri takip etmektedir. En az atıfla yapılan makale çalışma ise: "Strategic Thinking on Development of Air Logistics in Comprehensive Economic Experimental Community of Zhengzhou Airport"dur.

\section{Sonuç}

Hava lojistiği ile ilgili yapılan bibliyometrik araștırmada bilimsel iletişime ilişkin farklı bulgulara, belgelere ve yayınlara ulașılmıştır. Bu araştırmada yer alan atıf analizi çalışması hava lojistiği çalışmalarında sıklıkla kullanılan kaynakların belirlenmesine yönelik yapılmıştır. Hava lojistiği ile ilgili yapılan bibliyometrik çalışmada, hem literatür ölçülmüş hem de ortaya çıkan yeni konuların, kavramların yorumlanmasına yer verilmiștir. Araştırma kapsamında hava lojistiği alanında çalışılmamış konuların değerlendirilmesi ile ilgili araştırmacılara yön gösterici bir çalışma olmuştur.

$\mathrm{Bu}$ araștırmada hava lojistiği ile ilgili yapılan akademik çalıșmalar bibliyometrik analiz yöntemiyle tahlil edilmiștir. Çalıșmanın verileri, WOS, Scopus ve EBSCO veri tabanlarından toplanmış ve analiz edilmiştir. Bu bağlamda hava lojistiği alan yazınında en çok çalışılan disiplinler; "yöneylem araștırmaları, mühendislik bilimleri, ekonomi, pazarlama, çevre bilimi, tedarik zinciri, coğrafya, küreselleşme, bilgi teknolojileri, hukuk, istatistik" olarak bulunmuştur. Bu çalışma alanları hava lojistiğinin disiplinler arası bir çalışma alanı olduğunu göstermektedir.

Yöntemde belirtilen tarihte yapılan taramaya göre hava lojistiği ile ilgili en çok çalışma, 2013 yılında yapılmıștır. ABD başta olmak üzere Güney Kore, Almanya ve İngiltere hava lojistiği ile ilgili en çok yayınların yapıldığı ülkelerdir. Araştırma kapsamında hava lojistiği ile ilgili makalelerde en çok kullanılan anahtar kelimeler; "hava kargosu, hava taşımacılığı, havaalanı ve havalimanı, hava kargo işletmeciliği, lojistik ve navlun" olarak bulunmuştur.

Hava kargosu taşımacılık ağı, sürdürülebilir rekabet, tarife planlama, maliyet kontrolü, rezervasyon ve satış ve fazla satıș (overbooking) başlıklı konular hava lojistiği alan yazınında daha çok işlenmektedir. Hava lojistiği üzerine yazılan akademik çalışmaların yayınlanması için en çok tercih edildiği dergi; "Transportation Science" olarak bulunmuştur. Bu dergiyi ise sırasıyla: "Or Spectrum, Journal of Air Transportation, Applied Mathematical Modelling, The Information Society An International Journal..." izlemektedir.

Araştırma kapsamında değerlendirilen makaleler en çok Scopus veri tabanında taranmakla birlikte 10 tanesi de SSCI'de taranmaktadır. Hava lojistiği ile ilgili taranan 26 makalenin ve yazarının aldığı atıflar incelendiğinde; Amaruchkul ve diğerleri, Lin ve Chen, Chen ve Yeh en çok atıf alan yazarlardır. 26 Makaleye yapılan toplam atıf ise 489 olarak gerçekleşmiştir. En çok atıf alan ilk 10 dergide sadece bir tane yayın tek yazarlı olarak yayınlanmıştır. Diğer makaleler ortak yazarlıkla yayınlanmıştır.

Hava lojistiği üzerine hazırlanan 26 makalenin hazırlanma sürecinde en çok referans atıf yapılan makale: "Issues On Liberalization of Air Cargo Services in International Aviation"dır. Hava lojistiği araştırmalarına konu olan 26 makalenin kaynakça atıf sayıları incelendiğinde en çok kaynakça atıfı ile yazılan makale: "Core Competencies and Sustainable Competitive Advantage in Air-Cargo Forwarding: Evidence from Taiwan"dır. En az 5 kaynakça atıfıyla yazılan makale ise: "Strategic Thinking on Development of Air Logistics in Comprehensive Economic Experimental Community of Zhengzhou Airport"dur.

Araştırma kapsamında hava lojistiği ile ilgili yapılan bu çalıșmada en az çalışılmış alanlar; hava lojistik kümelenmesi, hava lojistiğinde küresel park, hava lojistiği 
entegrasyonu, hava kargosu için alternatif meydan seçimi, hava kargosu üzerine elektronik düzenlemelerdir.

Araștırma sonucunda elde edilen bulgulara göre araştırmacılara ve sektördeki paydaşlara ilişkin öneriler;

Araștırmacıların; hava lojistik kümelenmesi, hava lojistiğinde küresel park, hava lojistiği entegrasyonu, hava kargosu ve diğer konularda daha fazla akademik çalıșma yapması hava lojistiği literatürünü derinleştirecektir.

Uluslararası ticarette değer cinsinden diğer taşımacılık sistemlerine göre daha fazla ekonomi yaratan hava taşımacılığı faaliyetleri; gelecek yıllarda yatay ve dikey entegrasyonlar ile lojistik faaliyetlerde daha fazla bütünleşmelere giderek işletme stratejilerini değiştirecektir. Bu bağlamda hem ulusal hem de uluslararası hava kargo taşımacılığı yapan hava kargo işletmelerinin bu değişime göre işletme modellerini gözden geçirmeleri önemli bir stratejik karar olacaktır.

$\mathrm{Bu}$ çalışmayla hava lojistiği ile ilgili araştırma yapacak kişi ve kuruluşlara yol gösterilmeye çalıșılmıştır.

\section{KAYNAKÇA}

AL, U. \& COŞTUR, R. (2007). Türk psikoloji dergisinin bibliyometrik profili. Türk Kütüphaneciliği, 21(2), ss.142-163. Erișim adresi: https://dergipark.org.tr/en/pub/tk/issue/48938/624262

AMARUCHKUL, K., COOPER, W. L. \& GUPTA, D. (2007). Single-leg air-cargo revenue management. Transportation science, 41(4), 457-469. DOI: $10.1287 /$ trsc. 1060.0177

BENCKENDORFF, P. \& ZEHRER, A. (2013). A network analysis of tourism research. Annals of Tourism Research, 43, 121-149. DOI: 10.1016/j.annals.2013.04.005

BODENDORF, S. R. F. (1999). A framework for electronic coordination in the air cargo market. The Information Society, 15(1), 51-55. DOI: 10.1080/019722499128664

BOWEN J. R, J. T. \& LEINBACH, T. R. (2003). Air cargo services in Asian industrialising economies: Electronics manufacturers and the strategic use of advanced producer services. Papers in regional science, 82(3), 309-332. DOI: 10.1007/s10110003-0169-8

BROADUS, R. N. (1987). Toward a definition of "bibliometrics". Scientometrics, 12(5-6), 373-379. Erişim tarihi: https://link.springer.com/content/pdf/10.1007/BF02016680.pdf

CHENG, Y. \& YEH, C.(2017) Core competencies and sustainable competitive advantage in air-cargo forwarding: evidence from Taiwan. Transportation Journal, , 5-21. Erişim adresi: https://www.jstor.org/stable/20713676

CHUNG, T. W. (2009). A Study on Selections of Strategic Type of Business in Airlogistics Industry Clusters. The Asian Journal of Shipping and Logistics, 25(1), 83-102. DOI: 10.1016/S2092-5212(09)80014-X

CHUNG, T. W. \& HAN, J. K. (2013). Evaluating competitiveness of transshipment cargo in major airports in Northeast Asia: airport branding. The Asian Journal of Shipping and Logistics, 29(3), 377-394. DOI: 10.1016/j.ajsl.2013.12.005

DALKEY, N. \& HELMER, O. (1963). An experimental application of the Delphi method to the use of experts. Management science, 9(3), 458-467. DOI: $10.1287 /$ mnsc.9.3.458 DANYANG, S. (2013). Simulation of air cargo operations in West PACTL. Information Technology Journal, 12(15), 3179. DOI: 10.3923/itj.2013.3179.3183 
DE LIMA, M. G. \& BELDERRAIN, M. C. N. (2016). Structuring multicriteria model for airports selection for cargo airlines exclusively. Ingeniare. Revista chilena de ingeniería, 24(3), 465-479. Erișim adresi:

https://search.proquest.com/docview/1861772487?accountid=191718

DERIGS, U. \& FRIEDERICHS, S. (2013). Air cargo scheduling: integrated models and solution procedures. OR spectrum, 35(2), 325-362. DOI: doi.org/10.1007/s00291012-0299-y

DERIGS, U., FRIEDERICHS, S. \& SCHÄFER, S. (2009). A new approach for air cargo network planning. Transportation Science, 43(3), 370-380. DOI: 10.1287/trsc.1090.0282 Yayıncilı.

ERTURGUT, R. (2016). Lojistik ve Tedarik Zinciri Yönetimi. Ankara: Nobel

FENG, B., LI, Y. \& SHEN, Z. J. M. (2015). Air cargo operations: Literature review and comparison with practices. Transportation Research Part C: Emerging Technologies, 56, 263-280. DOI: 10.1016/j.trc.2015.03.028

FUNG, M. K. Y., ZHANG, A., LEUNG, L. C. K. \& LAW, J. S. (2005). The air cargo industry in China: implications of globalization and WTO accession. Transportation Journal, 44-62. Erişim adresi: http://www.jstor.org/stable/20713614

GARFIELD, E. (1972). Citation analysis as a tool in journal evaluation. Science, 178(4060), 471-479. DOI: 10.1126/science.178.4060.471

GEREDE, E. (2002). Havayolu taşımacıliğında küreselleșme ve havayolu ișbirlikleri-THY AO'da bir uygulama (Yayınlanmamış Doktora Tezi) Anadolu Üniversitesi Sosyal Bilimler Enstitüsü, Eskișehir.

GEREDE, E. (2006). Havacılık emniyeti ve havacılık güvenliği kavramları arasında ilişsi ve farkların belirlenmesine yönelik bir araștırma. İstanbul Üniversitesi İșletme İktisadi Enstitüsü Dergisi. 54, 26-37. Erişim adresi: https://kutuphane.dogus.edu.tr/mvt/pdf.php?recid=6272\&pdf $=0006262$

GEREDE, E. (2015). Havayolu taşımacılığı ve ekonomik düzenlemeler teori ve Türkiye uygulaması. Art Ofset Matbaacılık. Ankara.

HALLINGER, P. \& WANG, R. (2020). Analyzing the intellectual structure of research on simulation-based learning in management education, 1960-2019: A bibliometric review. The International Journal of Management Education, 18(3), 100418. DOI: $10.1016 /$ j.ijme.2020.100418

HOOD, W. W. \& WILSON, C. S. (2001). The literature of bibliometrics, scientometrics, and informetrics. Scientometrics, 52(2), 291. Erişim adresi: https://idp.springer.com/authorize/casa?redirect_uri=https://link.springer.com/article /10.1023/A:1017919924342\&casa_token=gT8190nG7RcAAAAA:ZU2E7YPs6WBTOt6fN k9_Xs7E3C4lwQKE-j_h7BG8nOU6dIVuj26P23N6lBWwQQJ7wzkY-DJIYDn1hGWg1w

HSU, W. K. (2011). A gap analysis in service quality for air freight forwarders. J. Chin. Inst. Transp, 23(4). Erişim adresi: https://www.scopus.com/record/display.uri?eid=2-s2.084974528921\&origin=inward\&txGid=0c670a7d17b21c95dc25cab6b7f03709\#

HU, Y. C., LEE, P. C., CHUANG, Y. S. \& CHIU, Y. J. (2018). Improving the sustainable competitiveness of service quality within air cargo terminals. Sustainability, 10(7), 2319. DOI: $10.3390 /$ su10072319

HUANG, S. H. S., TSENG, W. J. \& HSU, W. K. K. (2016). An assessment of knowledge gap in service quality for air freight carriers. Transport Policy, 50, 87-94. DOI: 10.1016/j.tranpol.2016.06.006

HULBERT, J. \& BINKLEY, J. (1977). Selling Strategy and Air Freight

Decisions. Transportation Journal, 61-69. Erişim adresi: http://www.jstor.org/stable/20712437 
IATA. (2018). International Air Transport Association Annual Review 2018. Erişim adresi:https://www.iata.org/publications/Documents/iata-annual-review-2018.pdf

ICAO. (2009). International Civil Aviation Organization, Review of The Classificatıon and Definitions used for Civil Aviation Activities. Erişim adresi: https://www.icao.int/meetings/sta10/documents/sta10_wp007_en.pdf

KAIN, K. \& VERMA, A. (2018). Logistics management in supply chain - an overview. Materials Today: Proceedings, 5 (2): 3811-3816. DOI: 0.1016/j.matpr.2017.11.634

KASILINGAM, R. G. (1997). An economic model for air cargo overbooking under stochastic capacity. Computers \& industrial engineering, 32(1), 221-226. DOI: 10.1016/S0360-8352(96)00211-2

KOEHLER, W. (2001). Information science as" Little Science": The implications of a bibliometric analysis of theJournal of the American Society for Information Science. Scientometrics, 51(1), 117-132. DOI: 10.1023/a:1010516712215

LARRODÉ, E., MUERZA, V. \& VILLAGRASA, V. (2018). Analysis model to quantify potential factors in the growth of air cargo logistics in airports. Transportation research procedia, 33, 339-346. DOI: 10.1016/j.trpro.2018.10.111

LAU, H. C., CHOY, K. L., LAU, P. K., TSUI, W. T. \& CHOY, L. C. (2004). An intelligent logistics support system for enhancing the airfreight forwarding business. Expert Systems, 21(5), 253-268. : DOI: 10.1111/j.1468-0394.2004.00283.x

LAKEW, P. A. (2014). Economies of traffic density and scale in the integrated air cargo industry: The cost structures of FedEx Express and UPS Airlines. Journal of Air Transport Management, 35, 29-38. DOI: 10.1016/j.jairtraman.2013.11.001

LAWANI, S. M. (1981). Bibliometrics: Its Theoretical Foundations, Methods and Applications. International Journal of Libraries and Information Services, Cilt: 31, Sayı: 4, ss. 294-315. DOI: 10.1080/10572317.2015.1113602?journalCode=ulbr20

LE, W. (2018). Application of wireless sensor network and RFID monitoring system in airport logistics. International Journal of Online and Biomedical Engineering (iJOE), 14(01), 89-103. : DOI: 10.3991/ijoe.v14i01.8058

LEUNG, X. Y., SUN, J. \& BAİ, B. (2017). Bibliometrics of social media research: A co-citation and co-word analysis. International Journal of Hospitality Management, 66, 35-45. DOI: 10.1016/j.ijhm.2017.06.012

LIN, C. C., LIN, J. Y. \& CHEN, Y. C. (2012). The capacitated p-hub median problem with integral constraints: An application to a Chinese air cargo network. Applied Mathematical Modelling, 36(6), 2777-2787. DOI: 10.1016/j.apm.2011.09.063

MANUAL, F. (2002). Proposed standard practice for surveys on research and experimental development. OECD Yayınlarl, ss. 202-204. DOI: 10.1787/19900414 MCLEAN, I. \& HEWITT, F. (eds.). (1994). Condorcet: foundations of social choice and political theory. Edward Elgar Publishing.

MENG, S. M., LIANG, G. S., LIN, K. \& CHEN, S. Y. (2010). Criteria for services of air cargo logistics providers: How do they relate to client satisfaction?. Journal of Air Transport Management, 16(5), 284-286. DOI: 10.1016/j.jairtraman.2010.02.003

MERIGÓ LINDAHL, J. \& YANG, J. B. (2017). A bibliometric analysis of operations research and management science. DOI: 10.1016/j.omega.2016.12.004

MIYASHITA, K. (2009). Structural change in the international advanced logistics. The Asian Journal of Shipping and Logistics, 25(1), 121-138. DOI: 10.1016/S2092-5212(09)80016-3

MÜSIAD (2015). İstanbul lojistik sektör analizi raporu (MÜSİAD Araştırma Raporları No: 95). İstanbul. 
NORIN, A., GRANBERG, T. A., YUAN, D. \& VÄRBRAND, P. (2012). Airport logisticsA case study of the turn-around process. Journal of Air Transport Management, 20, 3134. DOI: $10.1016 /$ j.jairtraman.2011.10.008

OKUBA, Y. (1997). Bibliometric Indicators and Analysis of Research Systems: Methods and Examples, OECD Science, Technology and Industry Working Papers, 1997/01, OECD Publishing. DOI: 10.1787/208277770603

PAQUAY, C., SCHYNS, M. \& LIMBOURG, S. (2016). A mixed integer programming formulation for the three-dimensional bin packing problem deriving from an air cargo application. International Transactions in Operational Research, 23(1-2), 187-213. DOI: 10.1111/itor.12111

PARASURAMAN, A., ZEITHAML, V. A. \& BERRY, L. L. (1985). A conceptual model of service quality and its implications for future research. Journal of marketing, 49(4), 41-50. DOI: 10.1177/002224298504900403

PRITCHARD, A. (1969). Statistical bibliography or bibliometrics. Journal of documentation, 25(4),348-349. Erişim adresi:

https://scholar.googleusercontent.com/scholar?q=cache:SSaN528B6AEJ:scholar.google. com/+Statistical+bibliography+or+bibliometrics\&hl=tr\&as_sdt=0,5\&as_vis=1

QIN, C. R., LUO, L., YOU, Y. \& XIAO, Y. X. (2012). An optimization model of the single-leg air cargo space control based on Markov decision process. Journal of Applied Mathematics, 2012. DOI: $10.1155 / 2012 / 235706$

RAZA, S. A., ASHRAFI, R. \& AKGUNDUZ, (2020). A. A bibliometric analysis of revenue management in airline industry. Journal of Revenue and Pricing Management, 130. DOI: $10.1057 / \mathrm{s} 41272-020-00247-1$

SALES, M. (2016). Aviation Logistics: The Dynamic Partnership Of Air freight And Supplychain. London; Phideladelpia: Kogan Page Publishers.

SARILGAN, A. E. (2011). Türkiye'de Bölgesel Havayolu Taşımacılığının Geliştirilmesi için Yapılması Gerekenler. Anadolu Üniversitesi Sosyal Bilimler Dergisi. 11(1), 69-88. Erişim adresi: http://www.acarindex.com/dosyalar/makale/acarindex1423869465.pdf

SCImago. (2019). About. Erişim adresi: https://www.scimagojr.com/aboutus.php

SENGUPTA, I. N. (1992). Bibliometrics, informetrics, scientometrics and librametrics: an overview. Libri, 42(2), 75. Erișim adresi: http://search.proquest.com/openview/f948efec425e7d23e1643125a1ad6a54/1?pqorigsite $=$ gscholar $\& \mathrm{cbl}=1818712$

SIT, V. (2004). Global transpark: New competitiveness for Hong Kong and South China based on air logistics. Geografiska Annaler: Series B, Human Geography, 86(3), 145163. DOI: $10.1111 / \mathrm{j} .0435-3684.2004 .00159 . x$

SONG, M. G. \& YEO, G. T. (2017). Analysis of the air transport network characteristics of major airports. The Asian Journal of Shipping and Logistics, 33(3), 117125. DOI: $10.1016 /$ j.ajsl.2017.09.002

TIE-JUN, C., KAI, K. \& MEI-LIANG, H. (2013). Dynamic Set Pair of AHP Method for Aviation Logistics Planning and Research. JApSc, 13(17), 3421-3425.

DOI: $10.3923 /$ jas.2013.3421.3425

TIMUR, N. (1998). Sanayi Isşletmelerinde Lojistik Faaliyetlerin Organizasyonu. Eskişehir: Anadolu Üniversitesi Yayınları.

TSAI, M. C. \& SU, Y. S. (2002). Political risk assessment on air logistics hub developments in Taiwan. Journal of Air Transport Management, 8(6), 373-380. DOI: 10.1016/S0969-6997(02)00016-9

ULAKBİM. (2019). Sıkça Sorulan Sorular. Erișim adresi:

https://cabim.ulakbim.gov.tr/bibliyometrik-analiz/bibliyometrik-analiz-sikca-sorulansorular/. 
WANG, H. (2015,). Study on development of aviation logistics industry in china. In 2015 3rd international conference on education, management, arts, economics and social science. Atlantis Press. pp.201-2048. DOI: 10.2991/icemaess-15.2016.45

WANG, X. \& LIU, C. (2014). Aviation Logistics Development Research. In 2014 International Conference on Mechatronics, Electronic, Industrial and Control Engineering (MEIC-14). Atlantis Press. Shenyang: China. DOI: 10.2991/meic-14.2014.382

WANG, Y. J. \& KAO, C. S. (2008). An application of a fuzzy knowledge system for air cargo overbooking under uncertain capacity. Computers ve Mathematics with Applications, 56(10), 2666-2675. DOI: 10.1016/j.camwa.2008.02.049

WEN, C. H., TSAI, M. C. \& LIN, C. H. (2011). Classification and competition analysis of air cargo logistics providers: Thecase of Taiwan's high-technology industry. Journal of Air Transport Management, 17(2), 106-109. DOI: 10.1016/j.jairtraman.2010.10.012

WILLIAM, G. W., SHOUKRY, S. N., PRUCZ, J. C. \& WILLIAM, M. M. (2016). Lightweight composite air cargo containers. SAE International Journal of Aerospace, 9(2016-01-2119), 185-189. DOI: 10.4271/2016-01-2119.

WU, P. J. \& YANG, C. K. (2018). Unstructured Big Data Analytics For Air Cargo Logistics Management. In 2018 IEEE International Conference on Service Operations and Logistics, and Informatics (SOLI): Singapore. DOI: 10.1109/SOLI.2018.8476741

XIAO-LI, Z. (2013). Strategic thinking on development of air logistics in comprehensive economic experimental community of Zhengzhou airport. Information Technology Journal, 12(19), 5346. DOI: 10.3923/itj.2013.5346.5349

XIONG, Y. (2014). Analysis of Development Factors of Central Plains Aviation Logistics Based on ISM. In 2014 2nd International Conference on EducationTechnology and Information System (ICETIS 2014). Jinan: China. DOI: 10.2991/icetis-14.2014.15 YILMAZ, M. (2019). Bibliyometriye eleştirel bir bakış. Türk Kütüphaneciliği, 33(1), 43-49. DOI: 10.24146/tkd.2019.47

YOON, S. H. \& PARK, J. W. (2015). A study of the competitiveness of airline cargo services departing from Korea: Focusing on the main export routes. Journal of Air Transport Management, 42, 232-238. DOI: 10.1016/j.jairtraman.2014.11.004

YU, D. \& XU, C. (2017). Mapping research on carbon emissions trading: a cocitation analysis. Renewable and Sustainable Energy Reviews, 74, 1314-1322. DOI: 10.1016/j.rser.2016.11.144

YUAN, X. M., LOW, J. M. \& TANG, L. C. (2010). Roles of the airport and logistics services on the economic outcomes of an air cargo supply chain. International journal of production economics, 127(2), 215-225. DOI: :10.1016/j.ijpe.2009.08.005

ZHANG, A. (2002). Electronic technology and simplification of customs regulations and procedures in air cargo trade. Journal of air transportation, 7(2). Erişim adresi: http://worldcat.org/oclc/49807676

ZHANG, A. \& ZHANG, Y. (2002a). Issues on liberalization of air cargo services in international aviation. Journal of Air Transport Management, 8(5), 275-287. DOI: 10.1016/S0969-6997(02)00008-X

ZHANG, A. \& ZHANG, Y. (2002b). A model of air cargo liberalization: passenger vs. all-cargo carriers. Transportation Research Part E: Logistics and Transportation Review, 38(3-4), 175-191. DOI: 10.1016/S1366-5545(02)00004-2

ZHAO, H., ZHANG, F. \& KWON, J. (2018). Corporate social responsibility research in international business journals: An author co-citation analysis. International Business Review, 27(2), 389-400. DOI: 10.1016/j.ibusrev.2017.09.006

ZHAO, M. (2012). Building collaboration system of air logistics service chain based on cloud computing. In 2012 Second International Conference on Business Computing and Global Informatization. Shanghai, China. DOI: 10.1109/BCGIN.2012.165 
ZHOU, W., KOU, A., CHEN, J. \& DING, B. (2018). A retrospective analysis with bibliometric of energy security in 2000-2017. Energy Reports, 4, 724-732. DOI: 10.1016/j.egyr.2018.10.012

ZHOU, X. (2015). The construction of evaluation index system of aviation logisticsindustry a case study of zhengzhou airport-based zone. In International Conference on Logistics Engineering, Management and Computer Science. Shengyang, China. DOI:10.2991/lemcs-15.2015.71

ZHU, L. \& YANG, X. (2011). Study on the relationship between Shanghai air logistics and international trade. Journal of System and Management Sciences, 1(2), 6875. Erişim adresi: https://www.semanticscholar.org/paper/Study-on-the-relationshipbetween-Shanghai-air-and-Zhu-

Yang/7842ca124ffdea3622b72931a52ac921cccc4630?p2df

\section{Summary}

Air logistics provides convenience and advantage for its stakeholders in the supply chain significantly with the continuous advance of world trade as it enables a rapid, punctual, safe and effective flow for goods, information and services in forward and backward direction all along the supply chain.

The aim of this study is to analyze papers on air logistics through bibliometrics and provide information about air logistics literature to researchers. Data used for the study to proceed was collected through data bases including Web of Science, Scopus and EBSCO. Data obtained in this scope is descriptively analyzed and scrutinized with the bibliometric analysis method. Citation analysis in the research was conducted to identify frequently used sources in air logistics studies. The research attained various findings, documents and papers on scientific communication. Both the literature was assessed and new topics as well as concepts were interpreted within the scope of obtained findings. In addition, under the bibliometrics research, in an independent manner considering the research area of air logistics, a guiding study focusing on different trends, that is, areas which were not discussed in previous studies was carried out.

Authors, keywords, citations, references in the bibliography, journals and other subfactors related to the topic of the study were visualized, tabulated and analyzed in Excel. Studies on air logistics were analyzed by years and 2013 was identified as the year with the highest number of academic studies. When studies were analyzed by country, it was seen that papers on air logistics were mostly published in "the United States, South Korea, Germany and the United Kingdom". The most frequently used keywords in papers regarding air logistics are as follows; "air cargo, air transportation, airfield and airport, air cargo operation, logistics and freight". Where studies on air logistics concentrate on is mostly air cargo transportation processes among flow processes. "Transportation Science" was considered as the most effective of journals in which 26 papers were published when journals including studies on air logistics and their impact factors were examined. Transportation Science is followed by "Or Spectrum, Journal of Air Transportation, Applied Mathematical Modelling, International Transactions Inoperational Research..." respectively. When the distribution of 26 scanned papers on air logistics in databases and indexes were reviewed, it was observed that 84\% of papers in Scopus database and 38\% of papers in SSCI index were scanned. While the number of citations from top 10 among 26 scanned papers and their authors was 418, the highest number of citations was from "Amaruchkul et al., Lin and Chen, Chen and Yeh". The total number of citations from 26 papers was 489. "Anming Zhang and Yimin Zhang" had the highest figure for reference citations with the paper titled "Issues on Liberalization of Air Cargo Services in International Aviation". When types of citations in 
papers in regards to air logistics were examined, it was observed that among top 10 papers there was a citation from just one book while all other citations were from papers.

Findings of the bibliometrics showed that air logistics works hand in hand with disciplines such as "operational research, engineering sciences, economy, marketing, environmental sciences, supply chain, geography, globalisation, information technologies, law and statistics. According to library studies on air logistics, the most frequently studied topics in the field of air logistics are; network design models in air cargo transportation, sustainable competition in air cargo industry, planning tariffs, reservation and sales strategies and overbooking. As for the least studied fields in air logistics, they include air logistics clustering, global parking in air logistics, air logistics integration, alternative area selection for air cargo, electronical arrangements on air cargo, and others. Based on findings and assessments reached, this study will be beneficial for researchers who will conduct studies in the field of air logistics by guiding them. 